\title{
Dynamic of Mangrove Associated Molluscs in Anthropized Areas of the Cameroon Coastline
}

\author{
Ernest Flavien Kottè-Mapoko', Vanessa Maxemillie Ngo-Massou², \\ Guillaume Léopold Essomè-Koum ${ }^{3}$, Laurant Nyamsi-Moussian ${ }^{4}$, \\ Alphonse Konango-Samè4, Boubakary ${ }^{4}$, Ndongo Din ${ }^{4}$
}

\footnotetext{
${ }^{1}$ Department of Fisheries Management, Institute of Fisheries and Aquatic Sciences at Yabassi, the University of Douala, Douala, Cameroon

${ }^{2}$ Department of Biological Sciences, Higher Teacher's Training College, the University of Yaoundé, Yaoundé, Cameroon ${ }^{3}$ Department of Aquatic Ecosystems Management, Institute of Fisheries and Aquatic Sciences at Yabassi, the University of Douala, Douala, Cameroon

${ }^{4}$ Department of Botany, Faculty of Sciences, the University of Douala, Douala, Cameroon

Email: *din.ndongo@yahoo.com
}

How to cite this paper: Kottè-Mapoko, E.F., Ngo-Massou, V.M., Essomè-Koum, G.L., Nyamsi-Moussian, L., Konango-Samè, A., Boubakary and Din, N. (2021) Dynamic of Mangrove Associated Molluscs in Anthropized Areas of the Cameroon Coastline. Open Journal of Ecology, 11, 565-579. https://doi.org/10.4236/oje.2021.118036

Received: May 27, 2021

Accepted: August 28, 2021

Published: August 31, 2021

Copyright (c) 2021 by author(s) and Scientific Research Publishing Inc. This work is licensed under the Creative Commons Attribution International License (CC BY 4.0).

http://creativecommons.org/licenses/by/4.0/

\section{(c) (i) Open Access}

\begin{abstract}
Due to unabated anthropogenic exploitations, mangrove forests globally are constantly under pressure and degradation, which may result in the reduction of ecosystem functioning and biodiversity. Molluscan fauna, which is one of the main macroinvertebrates that play a major ecological role in nutrient dynamics in mangroves, are sensitive to the changes in their habitat. This survey aims to assess the impact of anthropogenic activities on the diversity of molluscs' communities in the mangrove forest. Anthropogenic disturbances within 20 sampling sites were valued at six mangrove stands and patched scoring the degree of influence according to vegetation, structure, waste and trampling. Molluscs were caught by hand and counted within $1 \times 1 \mathrm{~m}^{2}$ plots placed at three points distant of $50 \mathrm{~m}$ established using a straight line transect of $100 \mathrm{~m}$. Upon the 20 sites investigated, five were slightly disturbed, eight moderately disturbed and seven sites were highly disturbed. The mean abundance of molluscs decreased from slightly disturbed areas $\left(172.25 \pm 73.09 \mathrm{Ind} \cdot \mathrm{m}^{-2}\right)$ to highly disturbed areas $\left(100.57 \pm 62.84 \mathrm{Ind} \cdot \mathrm{m}^{-2}\right)$. Highly disturbed areas have shown lower species richness $(R=1.09 \pm 0.15)$ and diversity $\left(H^{\prime}=2.30 \pm\right.$ 0.31 ). Human activities in the mangrove forest could particularly have effects on the diversity of molluscs, however, feature potential conservation measures have to be in harmony with the needs of the local population.
\end{abstract}

\section{Keywords}

Anthropogenic Disturbance Index, Human Activities, Level of Degradation, Mollusc Diversity 


\section{Introduction}

Anthropogenic activities are widely recognized as a driver of environmental impact due to the significant pressure they are recognized to generate. Almost all global mangrove losses that have occurred in the recent past decades are a result of anthropogenic pressures and anthropogenic edges. These losses are also evident in mangrove forests as this ecosystem is most at risk due to deforestation and reclamation [1] [2]. These anthropogenic pressures are mainly made necessary by the rapid coastal population growth [3]. Nowadays, although many studies have focused on mapping and quantifying mangrove loss, there are few comprehensive assessments on the impacts of mangrove degradation [4]. This, because mangrove habitats are regions of remarkable biological productivity [5] that provide food, breeding grounds and nursery sites for a variety of terrestrial and marine organisms [6].

Mollusca is represented by predators, herbivores, detritivores or filter feeders in the mangrove food web [7] and it is an important animal phylum, which inhabits the mangrove environment [8] [9]. Molluscs play a significant role in terms of providing food sources to aquatic animals, migratory birds, and humans. They form a key link in the food chain and have a high socioeconomic value for coastal fisheries [10]. Thus, molluscs are identified as an important biological indicator because molluscan diversity helps to assess the effect of environmental impacts on benthic ecosystem functioning [11]. Since they have the ability to assess water quality and ecological risk assessments, the mollusc population is greatly affected by changes in their habitat [12] [13]. In mangroves, molluscs can reach astonishingly high biomass and they occupy very different levels of the ecosystem food web. While gastropods contribute to entrap primary production within the system, both grazing fallen leaves and consuming mud (mainly composed by mangrove litter), bivalves are efficient filter feeders, able to capture suspended particles of various origins [7].

Mangrove associated molluscs diversity in Cameroon include 42 species [8]. Many authors have contributed to the knowledge of their taxonomy, diversity and distribution [8] [14] [15] [16]. However, in view of anthropogenic activities increasing on mangroves in Cameroon, these data are scarce and should be completed. A key question is how these faunistic communities behave in different anthropized habitats? This survey aims to assess the impact of anthropogenic activities on the diversity of molluscs' communities in the mangrove forest of $\mathrm{Ca}$ meroon.

\section{Materials and Methods}

\subsection{Study Area}

Twenty sites located in the Cameroon coastline were chosen according to mangrove scope in six localities, the importance of human activities in ecosystem and variability of the stands (Figure 1). The sites were distributed as follows: two sites in Limbe, three in Tiko, seven in Douala, three sites in Mouanko, three sites 


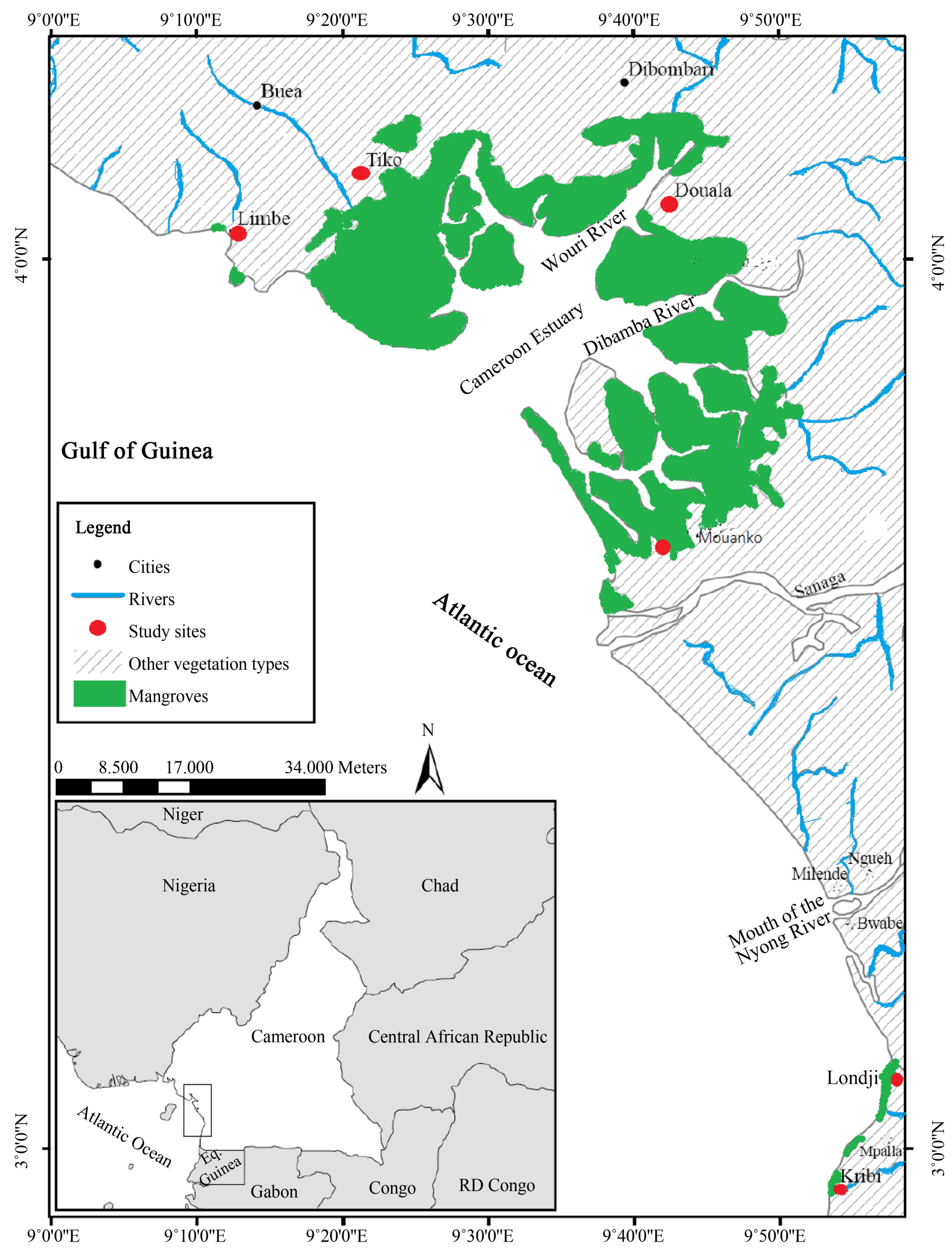

Figure 1. Localisation of study areas (adapted from [23]). 
in Kribi and Two in Londji (Table 1). Human activities within the mangrove habitats are the excessive harvest of mangrove trees for firewood, charcoal, clearing of mangrove areas for agricultural purposes coupled with the rapid urbanization of the adjacent towns and pollution [1] [17] [18] [19], which have led to a gradual degeneration of these ecosystems.

Two types of climate dominated the study area. In the northern and central parts, climate belongs to a particular equatorial regime called Cameroonian regime, characterized by a long rainy season (March-November) and a short dry season (December-February) with an annual average temperature of about $26.7^{\circ} \mathrm{C}$ [17]. Climate in the southern region is of a typical equatorial regime with four seasons (two rainy seasons and two dry seasons well individualized), marked by high and stable temperatures of about $28.7^{\circ} \mathrm{C}$. Heavy annual rainfalls are observed from more than $5000 \mathrm{~mm}$ in Limbe area and decreased to about $3000 \mathrm{~mm}$ in Kribi area. The tidal regime along the coastline reaches $3 \mathrm{~m}$ in the Cameroon Estuary, $1.2 \mathrm{~m}$ in the mouth of Nyong and $1.5 \mathrm{~m}$ in Kribi [20].

These three coastal regions are also distinguishable in terms of mangrove area (small patches in the South and large units in the Cameroon estuary and Rio del Rey estuary which gathered a great part of mangroves in Cameroon) and anthropogenic pressure [21]. Soils are gray or black muds, of silty, sandy or clay texture, and deriving from fluvial sediments [22]. The flora has consisted of seven

Table 1. Coordinates of different sampling sites.

\begin{tabular}{|c|c|c|c|}
\hline Localities & Sites & North latitude & East longitude \\
\hline \multirow{2}{*}{ Limbe } & Down beach & $04^{\circ} 00^{\prime} 40.64^{\prime \prime}$ & $09^{\circ} 10^{\prime} 21.67^{\prime \prime}$ \\
\hline & Mabeta & $04^{\circ} 00^{\prime} 10.42^{\prime \prime}$ & $09^{\circ} 12^{\prime} 25.74^{\prime \prime}$ \\
\hline \multirow{3}{*}{ Tiko } & Avion beach & $04^{\circ} 00^{\prime} 52.92^{\prime \prime}$ & $09^{\circ} 23^{\prime} 02.65^{\prime \prime}$ \\
\hline & Apollo beach & $04^{\circ} 00^{\prime} 56.35^{\prime \prime}$ & $09^{\circ} 23^{\prime} 43.58^{\prime \prime}$ \\
\hline & Mbomè & $04^{\circ} 00^{\prime} 07.14^{\prime \prime}$ & $09^{\circ} 17^{\prime} 33.79^{\prime \prime}$ \\
\hline \multirow{7}{*}{ Douala } & Bois des singes & $03^{\circ} 57^{\prime} 48.56^{\prime \prime}$ & $09^{\circ} 45^{\prime} 53.81^{\prime \prime}$ \\
\hline & Bonamouang & $04^{\circ} 05^{\prime} 03.90^{\prime \prime}$ & $09^{\circ} 42^{\prime} 57.64^{\prime \prime}$ \\
\hline & Bonamoussadi & $04^{\circ} 06^{\prime} 10.23^{\prime \prime}$ & $09^{\circ} 43^{\prime} 49.10^{\prime \prime}$ \\
\hline & Bonendallè & $04^{\circ} 07^{\prime} 21.46^{\prime \prime}$ & $09^{\circ} 39^{\prime} 09.14^{\prime \prime}$ \\
\hline & Essenguè & $04^{\circ} 01^{\prime} 07.62^{\prime \prime}$ & $09^{\circ} 40^{\prime} 16.84^{\prime \prime}$ \\
\hline & Pont du wouri & $04^{\circ} 04^{\prime} 18.36^{\prime \prime}$ & $09^{\circ} 42^{\prime} 17.08^{\prime \prime}$ \\
\hline & Village & $04^{\circ} 04^{\prime} 11.58^{\prime \prime}$ & $09^{\circ} 50^{\prime} 50.14^{\prime \prime}$ \\
\hline \multirow{3}{*}{ Mouanko } & Mbiako & $03^{\circ} 14^{\prime} 25.44^{\prime \prime}$ & $09^{\circ} 34^{\prime} 73.29^{\prime \prime}$ \\
\hline & Yoyo I & $03^{\circ} 50^{\prime} 18.02^{\prime \prime}$ & $10^{\circ} 03^{\prime} 45.37^{\prime \prime}$ \\
\hline & Yoyo II & $03^{\circ} 39^{\prime} 56.98^{\prime \prime}$ & $09^{\circ} 38^{\prime} 39.43^{\prime \prime}$ \\
\hline \multirow{2}{*}{ Londji } & Londji I & $03^{\circ} 04^{\prime} 27.36^{\prime \prime}$ & $09^{\circ} 58^{\prime} 46.82^{\prime \prime}$ \\
\hline & Londji II & $03^{\circ} 05^{\prime} 03.81^{\prime \prime}$ & $09^{\circ} 58^{\prime} 32.64^{\prime \prime}$ \\
\hline \multirow{3}{*}{ Kribi } & Mpalla & $03^{\circ} 00^{\prime} 33.99^{\prime \prime}$ & $09^{\circ} 57^{\prime} 09.00^{\prime \prime}$ \\
\hline & Mpolongwe & $03^{\circ} 01^{\prime} 49.27^{\prime \prime}$ & $09^{\circ} 57^{\prime} 50.90^{\prime \prime}$ \\
\hline & Nziou & $02^{\circ} 59^{\prime} 09.82^{\prime \prime}$ & $09^{\circ} 57^{\prime} 28.96^{\prime \prime}$ \\
\hline
\end{tabular}


indigenous or true mangrove species (Acrostichum aureum L., Avicennia germinans (L.) Stearn, Conocarpus erectus L., Laguncularia racemosa (L.) Gaertn. F, Rhizophora harrisonii Leechman, $R$. mangle L. and $R$. racemosa GFW Meyer) with the last species being the most dominant [1]. These species live in association with several others considered like associates. The faunal component includes vertebrates, such as birds, reptiles and fish, and a wide range of invertebrates, mainly crabs and molluscs which constitute the bulk of benthic diversity [8] [16] [22] [23].

\subsection{Assessment of Mangrove Damage}

To estimate degradation, human activities that occurred in mangrove in different sites were noticed. Anthropogenic disturbance within each site, associated with transect line, were valued and patch scoring the degree of degradation according to four (04) categorical variables:

- Vegetation (V): Evidence of logging on mangrove species and presence of invasive species.

- Trampling (T): The presence of human footprints.

- Waste (W): The presence of solid wastes on the forest floor and entangled on the roots.

- Structure (St): The evidence of human modifications of mangrove hydrology and/or topography.

According to the local situation, each variable was scored from 0 to 5 where:

- $0=$ absence of damage;

- 1 = very little damages;

- 2 = little damages;

- 3 = average damages;

- 4 = high damages;

- 5 = very high damages.

The score of each categorical variable was combined and summarized into Anthropogenic Disturbance Index (ADI). According to [24], values for each variable were average each local/site context and summarized as follows: $\mathrm{V}+\mathrm{T}$ $+\mathrm{W}+\mathrm{St}=\mathrm{ADI}$. Therefore, the ADI ranged from 0 to 20 which characterizes the mangrove degradation level. Three mangrove degradation levels (low, medium or moderate and high) were recognized, considering the value of ADI in any site:

- $0<\mathrm{ADI}<6$ equivalent to low degradation;

- $7<\mathrm{ADI}<12$ equivalent to moderate degradation;

- $\mathrm{ADI}>12$ equivalent to high degradation.

\subsection{Molluscs Sampling}

Molluscs were caught by hand and counted within $1 \times 1 \mathrm{~m}^{2}$ plots placed at three zones established using a straight line transect of $100 \mathrm{~m}$ perpendicular to the water shoreline in the mangrove vegetated area as mentioned by [25]. Arboreal 
species were also harvested by hand from roots and stems of mangrove trees [26]. To quantify abundance of molluscs, the transect is carefully looked through to search specimens that were not collected in the plots. Given the variability of each site, the distance between two transects was about $100 \mathrm{~m}$. Individuals were sorted out by eye, identified, when possible, in the field and counted. Fully unidentified collected molluscs were washed and preserved in $70 \%$ alcohol then were taken to laboratory for further identification using available data [14] [15] [16] and molluscs database (https://www.molluscabase.org/) websites.

\subsection{Data Analysis}

Depending on the presence/absence of each species and the number of its individuals in the different sites, the following annotations have been retained:

- $\quad-($ absent $)=$ no individual of the species was found;

- $+($ low recorded $)=$ species is present and its number of individuals is less than or equal to 5 ;

- $++($ medium recorded $)=$ species is present and its number of individuals is between 6 and 50;

- $+++($ high recorded $)=$ species is present and its number of individuals is greater than 50 .

The occurrence of the sample species was calculated as following [27]:

$$
F=\frac{P i}{P} \times 100
$$

where $F$ represent the frequency of occurrence (\%), $P i$ and $P$ are the sample sites where species $i$ is present and the total number of sites surveyed respectively.

The result obtained were used to qualified the species as rare $(0-15 \%)$, occasional $(15 \%-25 \%)$, common $(25 \%-50 \%)$, constant $(50 \%-75 \%)$ or ubiquitous (75\% - 100\%) [28].

The abundance and species richness (Margalef index) of different sites and relative density of each species were assessed, likewise, diversity index of Shannon-Weaver $\left(\mathrm{H}^{\prime}\right)$ and the evenness index of Pielou (J') of each site were calculated using PAST v 3.05" software. ADI, mean and standard deviation of data were assessed using Microsoft Office Excel 2019.

\section{Results}

\subsection{Mangrove Degradation Level}

Between different categorical variables choose to assess degradation, vegetation was highly affected in Apollo beach, Mbomè, Bois des Singes, Essenguè, Pont du Wouri, Village, Mpalla and Nziou. Trampling was well marked in down beach, Bois des Singes, Bonendalè, Essenguè, Village and Nziou. Concerning dumping of wastes in mangrove ecosystems, Bois des Singes was the most affected. The mangrove structure was highly altered at Pont du Wouri and Appolo Beach sites (Table 2). 
Table 2. Degradation level assessment and parameter structure of different sites: $\mathrm{V}=$ vegetation; $\mathrm{T}=$ trampling; $\mathrm{W}=$ waste; $\mathrm{St}=$ structure; $\mathrm{ADI}=$ Anthropogenic Disturbance Index; $\mathrm{N}=$ number of individuals; $\mathrm{S}=$ number of species; $\mathrm{P}=$ number of plots; $\mathrm{A}=$ Abundance $\left(\right.$ ind $\left.\cdot \mathrm{m}^{-2}\right) ; \mathrm{H}^{\prime}=$ Shannon-Weaver index; $\mathrm{R}=$ Margalef index; J' = Pielou evenness.

\begin{tabular}{|c|c|c|c|c|c|c|c|c|c|c|c|c|c|c|c|c|c|c|c|c|c|}
\hline \multirow{2}{*}{\multicolumn{2}{|c|}{$\begin{array}{c}\text { Localities } \\
\text { 芯 }\end{array}$}} & \multicolumn{2}{|c|}{ Limbe } & \multicolumn{3}{|c|}{ Tiko } & \multicolumn{7}{|c|}{ Douala } & \multicolumn{3}{|c|}{ Mouanko } & \multicolumn{2}{|c|}{ Londji } & \multicolumn{3}{|c|}{ Kribi } \\
\hline & & 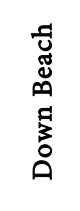 & 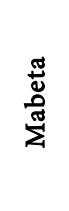 & 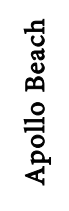 & 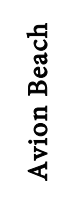 & $\begin{array}{l}\stackrel{0}{\Xi} \\
0 \\
\stackrel{2}{\Sigma}\end{array}$ & 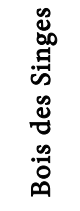 & 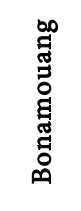 & 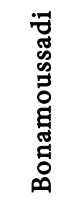 & 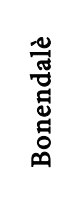 & 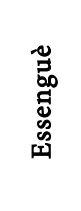 & $\begin{array}{l}\vec{E} \\
\vec{g} \\
3 \\
\vec{z} \\
\vec{z} \\
\vec{z} \\
0\end{array}$ & 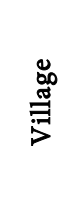 & $\begin{array}{l}\stackrel{0}{a} \\
\stackrel{3}{3} \\
\sum\end{array}$ & $\begin{array}{l}\text { 円 } \\
0 \\
0 \\
0\end{array}$ & 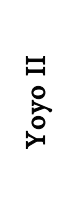 & 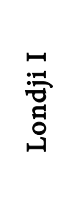 & 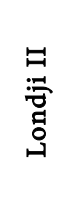 & 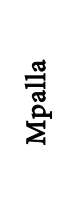 & $\begin{array}{l}0 \\
\sum_{0} \\
0 \\
0 \\
0 \\
\vdots \\
\sum\end{array}$ & $\begin{array}{l}\vec{Z} \\
\stackrel{D}{N} \\
Z\end{array}$ \\
\hline \multirow{5}{*}{ 总 } & $\mathrm{V}$ & 3 & 3 & 4 & 2 & 4 & 4 & 2 & 2 & 3 & 4 & 4 & 4 & 2 & 1 & 2 & 2 & 3 & 4 & 2 & 4 \\
\hline & $\mathrm{T}$ & 4 & 3 & 3 & 1 & 3 & 4 & 3 & 3 & 4 & 4 & 3 & 4 & 1 & 2 & 1 & 1 & 2 & 3 & 3 & 4 \\
\hline & $\mathrm{W}$ & 3 & 2 & 2 & 3 & 3 & 4 & 3 & 2 & 3 & 3 & 3 & 3 & 1 & 2 & 1 & 0 & 1 & 1 & 2 & 3 \\
\hline & St & 2 & 3 & 4 & 2 & 2 & 3 & 2 & 2 & 3 & 2 & 4 & 3 & 0 & 0 & 0 & 0 & 1 & 2 & 1 & 2 \\
\hline & ADI & 12 & 11 & 13 & 8 & 12 & 15 & 10 & 9 & 13 & 13 & 14 & 14 & 4 & 5 & 4 & 3 & 7 & 10 & 8 & 13 \\
\hline \multicolumn{2}{|c|}{ 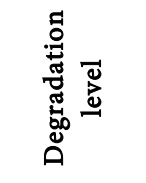 } & 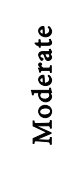 & 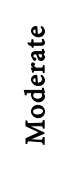 & 点 & 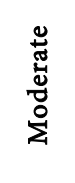 & 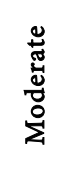 & 名 & 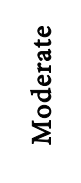 & 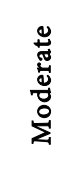 & 点 & 点 & 番 & 点 & 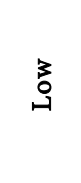 & క్ & ב3 & 艿 & 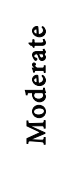 & 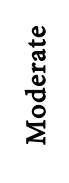 & 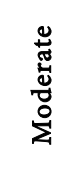 & 点 \\
\hline \multirow{7}{*}{ 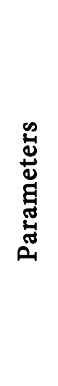 } & $\mathbf{N}$ & 1248 & 624 & 813 & 579 & 958 & 2103 & 6460 & 5181 & 1008 & 1291 & 196 & 1681 & 5127 & 3639 & 8343 & 790 & 1229 & 795 & 1445 & 576 \\
\hline & $S$ & 12 & 7 & 9 & 10 & 8 & 11 & 15 & 12 & 9 & 9 & 6 & 7 & 15 & 10 & 18 & 5 & 8 & 7 & 9 & 8 \\
\hline & $\mathbf{P}$ & 15 & 6 & 12 & 15 & 9 & 15 & 27 & 18 & 12 & 6 & 9 & 15 & 27 & 18 & 36 & 12 & 18 & 15 & 21 & 9 \\
\hline & A & 83 & 104 & 67 & 39 & 106 & 140 & 239 & 288 & 84 & 215 & 22 & 112 & 189 & 202 & 232 & 66 & 68 & 53 & 69 & 64 \\
\hline & $\mathrm{H}^{\prime}$ & 3.25 & 2.19 & 2.84 & 2.61 & 2.49 & 2.12 & 3.02 & 3.13 & 1.84 & 2.38 & 2.02 & 2.33 & 3.16 & 2.37 & 2.83 & 2.07 & 2.49 & 2.52 & 2.11 & 2.57 \\
\hline & $\mathbf{R}$ & 1.54 & 0.93 & 1.19 & 1.41 & 1.02 & 1.31 & 1.59 & 1.29 & 1.16 & 1.12 & 0.94 & 0.81 & 1.64 & 1.09 & 1.88 & 0.59 & 0.98 & 0.89 & 1.09 & 1.10 \\
\hline & $J^{\prime}$ & 0.91 & 0.78 & 0.89 & 0.79 & 0.83 & 0.61 & 0.77 & 0.87 & 0.58 & 0.75 & 0.78 & 0.83 & 0.81 & 0.71 & 0.68 & 0.89 & 0.83 & 0.89 & 0.67 & 0.85 \\
\hline
\end{tabular}

An assessment of the mangrove degradation, based on the scores of the variables affected by human activities is given in Figure 2 below. Among the 20 sites sampled, depending on the damage caused by human activities, the anthropogenic disturbance index (ADI) was higher in the Bois des Singes site (15) and lower in Londji I (3). This index permitted to distinguish four (04) slightly degraded sites (Mbiako, Londji I, Yoyo I and Yoyo II), nine (09) moderately degraded (Down beach, Londji II, Mabeta, Avion beach, Mbomè, Bonamouang, Bonamoussadi, Mpalla and Mpolongwe) and seven (07) highly degraded (Apollo beach, Bois des Singes, Bonendalè, Essenguè, Pont du Wouri, Village and Nziou).

\subsection{Molluscan Community Structure}

A total of 34 species of molluscs were collected during this study. They comprised two classes: Bivalvia (4 species) and Gastropoda (30 species). The list of different species collected is shown in Table 3. Pachymelania fusca showed higher occurrence percentage (100\%) found to be high recorded in the different assemblages, while most species with low occurrence percentage (5\%) showed 
Table 3. Presence of molluscs at different sites: Dob = Down Beach; Mab = Mabeta; Avb = Avion beach; Apb = Apollo beach; Mbo = Mbome, Bos = Bois des Singes; Bng = Bonamouang; Bdi = Bonamoussadi; Blè = Bonendalè; Ess = Essenguè; Pow = Pont $\mathrm{du}$ Wouri; Vil = Village; Mbi = Mbiako; YoI = Yoyo I; YoII = Yoyo II; LoI = Londji I; LoII = Londji II; Mpa = Mpalla; Mpo = Mpolongwe; Nzi = Nziou. (-) Absent; (+) Recorded; (++) Medium recorded; (+++) High recorded.

\begin{tabular}{lllllllll}
\hline \multirow{3}{*}{ Species } & Limbe & Tiko & Douala & & Mouanko & Londji & Kribi \\
\cline { 2 - 6 } & DobMabAvbApbMboBosBng Bdi & Blè & Ess Pow Vil Mbi YoI YoII LoI LoII Mpa Mpo Nzi \\
\hline
\end{tabular}

\section{Crassostrea gasar}

$++\quad-\quad++\quad+++++-$

Cyrenoida rosea

Egeria radiata

Iphegenia rostrata

Aachatina achatina

Littorina angulifera

Littorina sp.

Melanopsis sp.

Murex sp.

Neritilia rubida

Neritina andansoniania

Neritina glabrata

Neritina lineolata

Neritina senegalensis

UD1

UD2

UD3

UD4

Pachymelania aurita

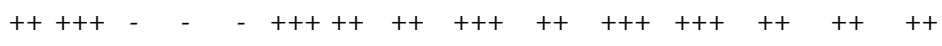

Pachymelania Byronensis

Pachymelania fusca

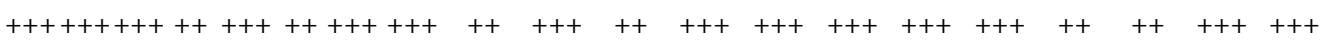

Pachymelania granifera

Pachymelania mutans

Pachymelania sp.

Pachymelania

quadriseriata

Potadoma liricincta

Tympanotonus fuscatus

$++++++++++\quad+++++++++\quad++\quad-\quad+++\quad+++\quad+++\quad+++\quad+++\quad+++\quad+++\quad+++\quad+++\quad+++\quad+$

Tympanotonus radula

$+++++++++++++++++++++++\quad+++\quad+++\quad+++\quad+++\quad++\quad++\quad+++\quad+++\quad+++\quad+++\quad+++\quad-$

Thais callifera

Theodoxus niloticus

Theodoxus sp.

Melanopsis pergracilis

Melanoides tuberculata

UD5 


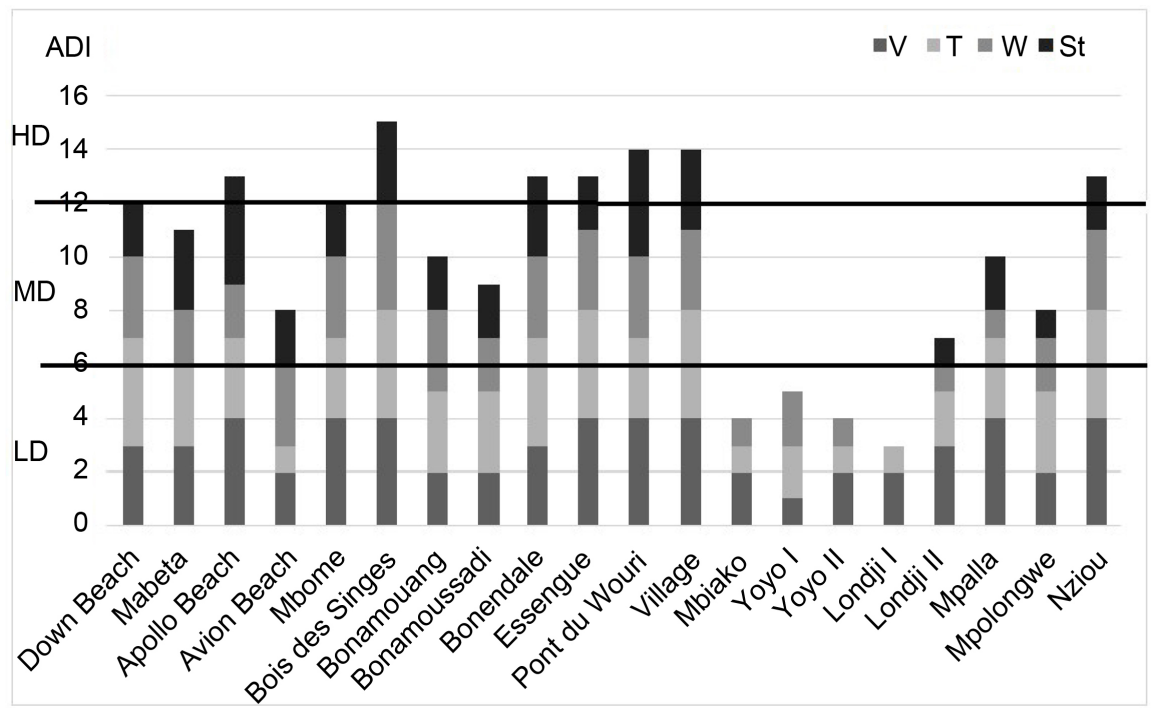

Figure 2. Degradation level of different sites: ADI = Anthropogenic Disturbance Index; $\mathrm{LD}=$ Low degradation; $\mathrm{MD}=$ Moderate degradation; $\mathrm{HD}=$ High degradation .

low numbers of individuals in the sites where they were presents. However, Potadoma liricincta is medium recorded in Bonamouang although with a low percentage of occurrence. The bivalve Crassostrea gasar is medium recorded or high recorded in the sites where it was collected (medium recorded at Down beach; Apollo beach and Avion beach; high recorded at Mbomè, Londji II and Mpalla.

Figure 3 shows distribution of occurrence among these species. Six species are rare (Cyrenoida rosea, Potadoma liricincta, UD1, UD2, UD3 and UD4), fourteen species are uncommon or occasionals (Egeria radiata, Iphegenia rostrata, Littorina sp., Melanopsis sp., Murex sp., Neritilia rubida, Neritina adansoniana, $N$. lineolata, N. senegalensis, Pachymelania byronensis, P. quadriseriata, Theodoxus sp., Melanopsis pergracilis and UD5), nine species are commons (Crassostrea gasar, Achatina achatina, Littorina angulifera, Neritina glabrata, Pachymelania granifera, P. mutans, Pachymelania sp., Thais callifera and Melanoides tuberculata), two are constants (Pachymelania aurita and Theodoxux niloticus) and three species are ubiquitous (Pachymelania fusca, Tympanotonus fuscatus and Tympanotonus radula).

\subsection{Effect of Mangrove Degradation}

Following classification of mangrove based on anthropogenic disturbance index (ADI), abundance of molluscs, species richness and diversity index given are the means of cumulative sample values in different sampling sites. Globally, slightly differences were observed in abundance of molluscs, species richness and Shannon-Weaver index among degradation levels of mangrove stands (Figure 4). The abundance of molluscs and species richness were higher (respectively $\mathrm{D}=$ $172.25 \pm 73.09 \mathrm{Ind} \cdot \mathrm{m}^{2}$ and $\mathrm{R}=1.29 \pm 0.56$ ) in areas with a low degradation level. Areas with high degradation level presented low values of abundance $(\mathrm{D}=$ 


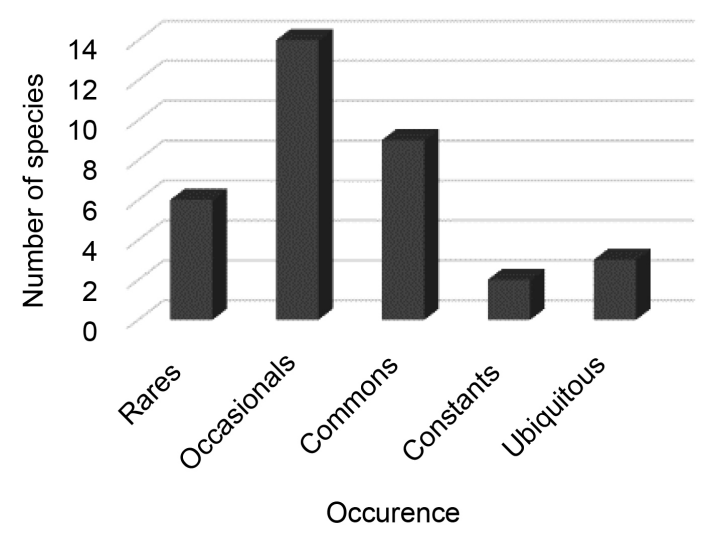

Figure 3. Occurrence of molluscs collected.

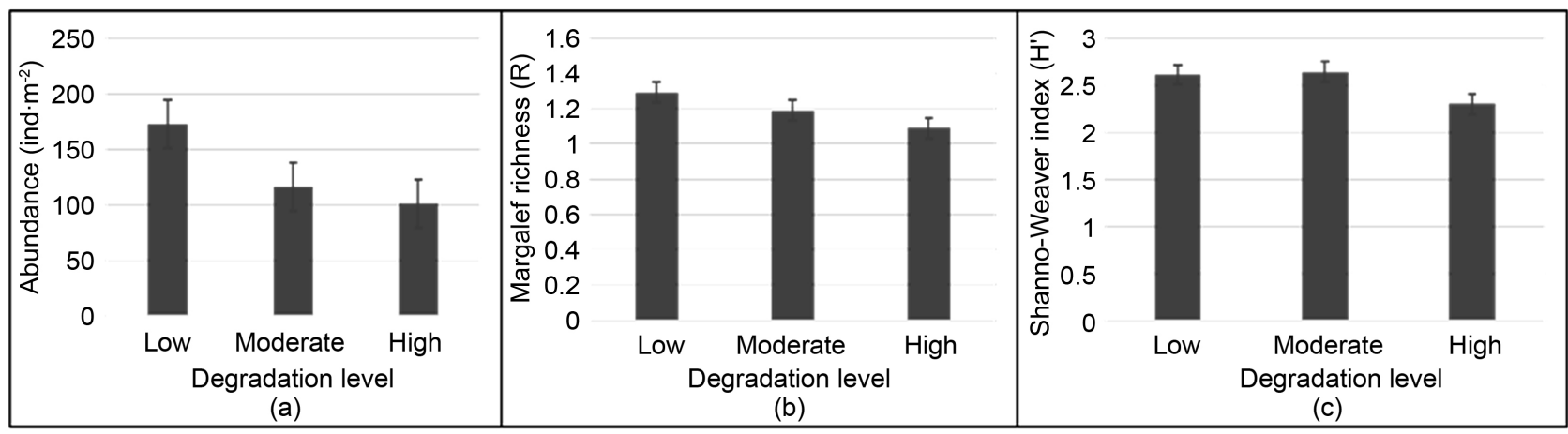

Figure 4. Variation of molluscan communities according to mangrove degradation level: (a) Abundance; (b) Margalef richness index; (c) Shannon-Weaver diversity index.

$\left.100.57 \pm 62.84 \mathrm{Ind} \cdot \mathrm{m}^{-2}\right)$, of species richness $(\mathrm{R}=1.09 \pm 0.15)$ and of Shannon-Weaver index $\left(\mathrm{H}^{\prime}=2.30 \pm 0.31\right)$. The high value of mean Shannon-Weaver diversity index was found in moderate degradation level $\left(H^{\prime}=2.64 \pm 0.40\right)$.

\section{Discussion}

The observations made in the various study areas have shown that all the mangrove stands were disturbed, but at different levels. Human activities have a massive impact on mangrove forests, especially their deforestation [29]. These impacts can significantly transform forests by triggering negative effects on the entire ecosystem assembly resulting in reduced biodiversity and functionality [30]. Among the anthropogenic activities identified, logging is the main cause of partial or complete deforestation of large spaces of mangroves, thus promoting rampant urbanization in coastal regions [1]. Observations made in this work have shown that vegetation is the most affected variable, thus presenting, in major sites, scores greater or equal to 3. In non-peri-urban mangroves (Londji and Mouanko), fishing is always the main activity. For local residents, fish smoking is well developed, and as a result, the wood of red mangroves (Rhizophora spp.) is highly prized for drying fish because of its high resin content and its ability to burn at fresh [31]. However, the level of disturbance is low in non-peri-urban mangroves (low degradation in the sites of Londji I, Londji II, Mbiako, Yoyo and 
Yoyo II) in comparison with peri-urban mangroves.

The consequences of urban development vary according to region and so far, remain only roughly predictable [32]. However, with regard to the impacts of urbanization on habitats and living organisms, as well as the urbanization factors responsible for these effects, certain trends emerge from the literature. Human footprints such as the construction of houses and infrastructure are observed in most of the peri-urban mangroves of Douala, Limbe and Kribi. The realization of development projects, in particular the construction of Wouri second bridge and the anarchic urbanization, which pushes the populations to occupy the mangrove areas, are all disturbances of human origin [1]. These activities are responsible for severe impacts in these ecosystems: Changing or completely degrading the physical structure of the mangrove, and affecting the abundance and distribution of benthic macrofauna and therefore molluscs as reported by [33].

Anthropogenic stress is the response of a biological entity, or any individual, population, or community, to anthropogenic disturbance. This stress at one level of the organization can also have an impact on another level. Since it is difficult to detect the effects of anthropogenic stress at the individual level, they are very often sought at the level of populations or communities [34]. The specific impacts of anthropogenic activities on the diversity and abundance of molluscs could vary depending on the low, medium or high level of human disturbance, the geographical location, the presence of pollutants in the sediments, the dynamics of nutrients and the extent of spatial modifications [13] [35]. This work has shown that the abundance, specific richness and diversity of molluscs were affected by human activities that have taken place in the mangroves. These results are in conformity with the work of many authors who have shown that habitat degradation and fragmentation are typically associated with a loss of species diversity, richness and evenness [25] [36] [37]. The high molluscan diversity in mangroves is mainly due to availability of a diverse range of microhabitats [10]. The distribution and diversity of molluscs depend on several physico-chemical factors, but the underlying factor is the habitat wherein they thrive [11]. [38] suggested that the impacts generated by human activities would be changes in the dynamics of tidal flooding and, therefore, the distribution of leaves in the substrate resulting in a decrease in mollusc abundance in affected areas. [39] also concluded that an extreme impact could greatly reduce abundance of molluscs due to the change in the level of flooding, tide and through the availability of organic matter in the sediment. However, in accordance with these authors, mollusc abundance may be altered by human impacts causing fragmentation in the system because intra and interspecific interactions would be affected. However, in this work, the highest diversity was found in moderately degraded areas. These results have suggested that when the environment is not too affected by human activities, a good number of functions are still performed because human impacts participated also to the normal evolution of an ecosystem. If the mangrove is not too degraded, new conditions (e.g. presence of debris from human activities that can serve as habitats for benthic macrofauna) are created favour- 
ing the establishment of other species [4]. Small-scale changes in mangrove structure can affect the diversity and abundance of benthic organisms in these habitats [10] [13].

\section{Conclusion}

Mangrove forests in Cameroon are suffered from habitat destruction and fragmentation. This is shown in this study by the method used to assess the anthropogenic disturbance index which has permitted to discriminate the twenty sampling sites in seven highly degraded, nine moderately degraded and four slightly degraded. This situation may result in a severe reduction in mangrove biodiversity and disturbance ecosystem functioning. The present work has reported that abundance, species richness and diversity index of molluscs are lower in highly degraded mangroves when compared with slightly and moderate degraded areas. These results provided indicators for mangrove features under the anthrone classification and reflected the importance of habitats for the conservation of sensitive biocenoses as macrobenthos and highlighted the need for further understanding the effects of anthropogenic stressors on mangrove ecosystems. Human activities on the mangrove forest could particularly have effects on the diversity of molluscs, however, to mitigate the above impacts to a great extent, feature potential conservation measures have to be in harmony with the needs of the local population.

\section{Acknowledgements}

E.F. K-M would like to express his gratitude to the organization IDEA WILD for providing some of the equipment needed for this work.

\section{Conflicts of Interest}

The authors declare no conflicts of interest regarding the publication of this paper.

\section{References}

[1] Din, N., Ngo-Massou, V.M., Essomè-Koum, G.L., Ndema-nsombo, E., Kottè-Mapoko, E.F. and Nyamsi-Moussian, L. (2017) Impact of Urbanization on the Evolution of Mangrove Ecosystems in the Wouri River Estuary (Douala Cameroon). In: Finkl, C.W. and Makowski, C., Eds., Coastal Wetlands. Alteration and Remediation, Vol. 21, Springer, Cham, 81-131. https://doi.org/10.1007/978-3-319-56179-0_3

[2] Kauffman, J.B., Bernardino, A.F., Ferreira, T.O., Bolton, N.W., Gomes, L.E.O. and Nobrega, G.N. (2018) Shrimp Ponds Lead to Massive Loss of Soil Carbon and Greenhouse Gas Emissions in Northeastern Brazilian Man-Groves. Ecology and Evolution, 8, 5530-5540. https://doi.org/10.1002/ece3.4079

[3] UNEP (United Nations Environment Programme) (2014) The Importance of Mangroves to People: A Call to Action. World Conservation Monitoring Center, Cambridge, $128 \mathrm{p}$.

[4] Carugati, L., Gatto, B., Rastelli, E., Lo Martire, M., Coral, C., Greco, S. and Danova- 
ro, R. (2018) Impact of Mangrove Forests Degradation on Biodiversity and Ecosystem Functioning. Scientific Reports, 8, Article No. 13298 https://doi.org/10.1038/s41598-018-31683-0

[5] Alongi, D.M. (2018) Impact of Global Change on Nutrient Dynamics in Mangrove Forests. Forests, 9, Article No. 596. https://doi.org/10.3390/f9100596

[6] Nagelkerken, I., Blaber, S.J.M., Bouillon, S., Green, P., Haywood, M., Kirton, L.G. and Somerfield, P.J. (2008) The Habitat Function of Mangroves for Terrestrial and Marine Fauna: A Review. Aquatic Botany, 89, 155-185. https://doi.org/10.1016/j.aquabot.2007.12.007

[7] Cannicci, S., Burrows, D., Fratini, S., Lee, S.Y., Smith III, T.J., Offenberg, J. and Dahdouh-Guebas, F. (2008) Faunistic Impact on Vegetation Structure and Ecosystem Function in Mangrove Forests: A Review. Aquatic Botany, 89, 186-200. https://doi.org/10.1016/j.aquabot.2008.01.009

[8] Kottè-Mapoko, E.F., Ngo-Massou, V.M., Essomè-Koum, L.G., Emane, J.M., Nyamsi-Moussian, L., Tchoffo, R. and Din, N. (2017) Molluscs' Composition and Distribution in Mangroves of the Cameroon Central Coast. International Journal of Research Studies in Biosciences, 5, 4-13.

[9] Zvonareva, S.S., Mekhova, E.S., Hà, V.T. and Kantor, Y.I. (2019) Checklist of Bivalve Molluscs in Mangroves of Khánh Hòa Province, Vietnam. Molluscan Research, 39, 296-312. https://doi.org/10.1080/13235818.2019.1638567

[10] Kabir, M., Abolfathi, M., Hajimoradloo, A., Zahedi, S., Kathiresan, K. and Goli, S. (2014) Effect of Mangroves on Distribution, Diversity and Abundance of Molluscs in Mangrove Ecosystem: A Review. AACL Bioflux, 7, 286-300.

[11] Al-Khayat, J.A., Vethamony, P. and Nanajkar, M. (2021) Molluscan Diversity Influenced by Mangrove Habitat in the Khors of Qatar. Wetlands, 41, Article No. 45. https://doi.org/10.1007/s13157-021-01441-6

[12] Susan, V.D., Pillai, N.G.K. and Satheeshkumar, P. (2012) A Checklist and Spatial Distribution of Molluscan Fauna in Minicoy Island, Lakshadweep, India. World Journal of Fish and Marine Sciences, 4, 449-453.

[13] Saad, L.O., Cunha, C.M. and Colpo, K.D. (2019) How Mollusk Assemblages Respond to Different Urbanization Levels: Characterization of the Malacofauna in Subtropical Brazilian Mangroves. Marine Biodiversity, 49, 989-999. https://doi.org/10.1007/s12526-018-0883-8

[14] Plaziat, J.C. (1974) Répartition des mollusques amphibies de quelques littoraux et estuaires à mangroves (Nouvelle Calédonie et Cameroun). Haliotis, 4, 167-177.

[15] Bandel, K. and Kowalke, T. (1999) Gastropod fauna of the Cameroonian coasts. Helgoland Marine Research, 53, 129-140. https://doi.org/10.1007/s101520050016

[16] Ngo-Massou, V.M., Essomè-Koum, G.L., Ngollo-Dina, E. and Din, N. (2012) Composition of Macrobenthos in the Wouri River Estuary Mangrove, Douala, Cameroon. African Journal of Marine Science, 34, 349-360.

https://doi.org/10.2989/1814232X.2012.725288

[17] Din, N., Saenger, P., Dibong, D.S., Priso, R.J. and Blasco, F. (2008) Logging Activities in Mangrove Forests: A Case Study of Douala Cameroon. African Journal of Environmental Science and Technology, 2, 22-30.

[18] Nfotabong-Atheull, A., Din, N. and Dahdouh-Guebas, F. (2013) Qualitative and Quantitative Characterization of Mangrove Vegetation Structure and Dynamics in a Peri-Urban Setting of Douala (Cameroon): An Approach Using Air-Borne Imagery. Estuaries and Coasts, 36, 1181-1192. https://doi.org/10.1007/s12237-013-9638-8

[19] Fusi, M., Beone, G.M., Suciu, N.A., Sacchi, A., Trevisan, M., Capri, E., Daffonchio, 
D., Din, N., Dahdouh-Guebas, F. and Cannicci, S. (2016) Ecological Status and Sources of Anthropogenic Contaminants in Mangroves of the Wouri River Estuary (Cameroon). Marine Pollution Bulletin, 109, 723-733.

https://doi.org/10.1016/j.marpolbul.2016.06.104

[20] Giresse, P., Megope-Foonde, J.P., Ngueutchoua, G., Aloisi, J.C., Kuete, M. and Monteillet, J. (1996) Carte sédimentologique du plateau continental du Camerounà à $1 / 200000$. ORSTOM, Paris.

[21] Nfotabong-Atheull, A. (2011) Impact of Anthropogenic Activities on the Vegetation Structure of Mangrove Forests in Kribi, the Nyong River Mouth and Cameroon Estuary. PhD Thesis, Université Libre de Bruxelles-ULB, Brussels, Belgium/The University of Douala, Cameroon.

[22] Ngo-Massou, V.M., Din, N., Kenne, M. and Dongmo, A.B. (2018) Brachyuran Crab Diversity and Abundance Patterns in the Mangroves of Cameroon. Regional Studies in Marine Science, 24, 324-335. https://doi.org/10.1016/j.rsma.2018.09.010

[23] Din, N., Ngo-Massou, V.M., Kottè-Mapoko, E.F., Essoh-Mongo, M.C. and Essomè-koum, G.L. (2014) Evolution of Mangrove Crabs Distribution in the Atlantic Coast of Cameroon. In: Ardovini, C., Ed., Crabs Global Diversity, Behavior and Environmental Threats, Nova Science Publishers Inc., New York, 161-180.

[24] Blanco-Libreros, J.F. and Estrada-Urrea, E.A. (2015) Mangroves on the Edge: Anthrome-Dependent Fragmentation Influences Ecological Condition (Turbo, Colombia, Southern Caribbean). Diversity, 7, 206-228. https://doi.org/10.3390/d7030206

[25] Rodrigues, C.A.L., Ribeiro, R.P., Santos, N.B. and Almeida, Z.S. (2016) Patterns of Mollusc Distribution in Mangroves from the São Marcos Bay, Coast of Maranhão State, Brazil. Acta Amazonica, 46, 391-400. https://doi.org/10.1590/1809-4392201600493

[26] Imakulata, M.M. and Tokan, M.K. (2018) Species Composition, Density and Dominance of Arboreal Mangrove Molluscs on the Paradiso Beach of Kupang City, Indonesia. AACL Bioflux, 11, 1001-1008.

[27] Dajoz, R. (1985) Precis d'écologie. Dunod, Paris, 489 p.

[28] Tessier, E., (2005) Dynamique des peuplements ichtyologiques associés aux récifs artificiels à l'île de la Réunion (ouest de l'océan Indien) - Implication dans la gestion des pêcheries côtières. Thèse de doctorat, Université de la Réunion, Réunion, 236 p.

[29] Hutchison, J., Manica, A., Swetnam, R., Balmford, A. and Spalding, M. (2013) Predicting Global Patterns in Mangrove Forest Biomass. Conservation Letter, 7, 233-240. https://doi.org/10.1111/conl.12060

[30] Butchart, S.H., Walpole, M., Collen, B., Van Strien, A., Scharlemann, J.P., Almond, R.E. and Watson, R. (2010) Global Biodiversity: Indicators of Recent Declines. Science, 328, 1164-1168. https://doi.org/10.1126/science.1187512

[31] Walters, B.B., Ronnback, P.P., Kovacs, J.M., Crona, B., Hussain, S.A., Badola, R., Primavera, J.H., Barbier, E. and Dahdouh-Guebas, F. (2008) Ethnobiology, Socio-Economics and Management of Mangrove Forests: A Review. Aquatic Botany, 89, 220-236. https://doi.org/10.1016/j.aquabot.2008.02.009

[32] Walsh, C.J., Roy, A.H., Feminella, J.W., Cottingham, P.D., Groffman, P.M. and Morgan, R.P. (2005) The Urban Stream Syndrome: Current Knowledge and the Search for a Cure. Journal of the North American Benthological Society, 24, 706-723.

https://doi.org/10.1899/04-028.1

[33] Beasley, C.R., Fernandes, C.M., Gomes, C.P., Brito, B.A., Dos Santos, S.M.L. and Tagliaro, C.H. (2005) Molluscan Diversity and Abundance among Coastal Habitats 
of Northern Brazil. Ecotropica, 11, 9-20.

[34] Jenouvrier, S., Barbraud, C. and Weimerskirch, H. (2003) Effects of Climate Variability on the Temporal Population Dynamics of Southern Fulmars. Journal of Animal Ecology, 72, 576-587. https://doi.org/10.1046/j.1365-2656.2003.00727.x

[35] Lee, S.Y., Primavera, J.H., Dahdouh-Guebas, F., Mckee, K., Bosire, J.O., Cannicci, S. and Record, S. (2014) Ecological Role and Services of Tropical Mangrove Ecosystems: A Reassessment. Global Ecology and Biogeography, 23, 726-743. https://doi.org/10.1111/geb.12155

[36] Aviz, D., Rodrigues, I.L. and Rosa-Filho, J.S. (2012) Spatial and Temporal Changes in Macrobenthic Communities in the Amazon Coastal Zone (Guajará Estuary, Brazil) Caused by Discharge of Urban Effluents. Scientia Marina, 76, 381-390. https://doi.org/10.3989/scimar.03312.16C

[37] Primavera, J.H., Friess, D.A., Van Lavieren, H. and Lee, S.Y. (2019) The Mangrove Ecosystem. In: Sheppard, C., Ed., World Seas: An Environmental Evaluation: Eco logical Issues and Environmental Impacts, Vol. 3, Academic Press, Waltham, 1-34. https://doi.org/10.1016/B978-0-12-805052-1.00001-2

[38] Skilleter, G.A. and Warren, S. (2000) Effects of Habitat Modification in Mangroves on the Structure of Mollusc and Crab Assemblages. Journal of Experimental Marine Biology and Ecology, 244, 107-129. https://doi.org/10.1016/S0022-0981(99)00133-1

[39] Chapman, M.G., Michie, K. and Lasiak, T. (2005) Responses of Gastropods to Change in Amounts of Leaf Litter and Algae in Mangrove Forests. Journal of the Marine Biological Association of the United Kingdom, 85, 1481-1488. https://doi.org/10.1017/S0025315405012671 